University of Nebraska - Lincoln

DigitalCommons@University of Nebraska - Lincoln

\title{
Oral inoculation with Salmonella enterica serovar Typhimurium or Choleraesuis promotes divergent responses in the somatotropic growth axis of swine
}

\author{
B. L. Davis
}

Kansas State University

J. N. Fraser

Kansas State University

Thomas E. Burkey

University of Nebraska-Lincoln, tburkey2@unl.edu

\section{K. A. Skjolaas \\ Talecris Biotherapeutics}

S. S. Dritz

Kansas State University

See next page for additional authors

Follow this and additional works at: https://digitalcommons.unl.edu/animalscifacpub

Part of the Animal Sciences Commons

Davis, B. L.; Fraser, J. N.; Burkey, Thomas E.; Skjolaas, K. A.; Dritz, S. S.; Johnson, B. J.; and Minton, J. E., "Oral inoculation with Salmonella enterica serovar Typhimurium or Choleraesuis promotes divergent responses in the somatotropic growth axis of swine" (2010). Faculty Papers and Publications in Animal Science. 701.

https://digitalcommons.unl.edu/animalscifacpub/701

This Article is brought to you for free and open access by the Animal Science Department at DigitalCommons@University of Nebraska - Lincoln. It has been accepted for inclusion in Faculty Papers and Publications in Animal Science by an authorized administrator of DigitalCommons@University of Nebraska - Lincoln. 


\section{Authors}

B. L. Davis, J. N. Fraser, Thomas E. Burkey, K. A. Skjolaas, S. S. Dritz, B. J. Johnson, and J. E. Minton 


\title{
Oral inoculation with Salmonella enterica serovar Typhimurium or Choleraesuis promotes divergent responses in the somatotropic growth axis of swine ${ }^{1}$
}

\author{
B. L. Davis, ${ }^{*}$ J. N. Fraser, ${ }^{*}$ T. E. Burkey, ${ }^{* 2}$ K. A. Skjolaas, ${ }^{* 3}$ S. S. Dritz, $\dagger$ \\ B. J. Johnson, ${ }^{* 4}$ and J. E. Minton ${ }^{* 5}$ \\ *Department of Animal Sciences and Industry, Weber Hall, Kansas State University, Manhattan 66506-0201; \\ and $\nmid$ Department of Diagnostic Medicine/Pathobiology, Kansas State University, Manhattan 66506-5601
}

\begin{abstract}
Enteric disease and immune challenge are processes that have detrimental effects on the growth performance of young swine. The current study tested the hypothesis that salmonella-induced enteric disease would perturb the endocrine growth axis in a serovar-dependent fashion. Specifically, we evaluated the effects of Salmonella enterica serovar Typhimurium (Typhimurium) and serovar Choleraesuis (Choleraesuis) on critical regulatory components of growth in young swine. Weaned pigs were housed 2 per pen with ad libitum access to feed and water in a 14-d experiment. Pigs were then repeatedly fed $10^{8}$ cfu of either Choleraesuis or Typhimurium in dough balls, with control pigs receiving dough without bacteria. Bacteria were refed twice weekly. Rectal temperatures were monitored daily from d 0 to 7 and ADFI was measured through d 14. Pigs were weighed and samples of serum were obtained for circulating IGF-I on d 0, 7, and 14 . At the conclusion of the study, samples of semitendinosus muscle and liver were obtained and subsequently assayed for IGF-I, IGFBP-3, and IGFBP-5 mRNA. Rectal temperatures were elevated in pigs given Choleraesuis from d 2 through $7(P<0.05)$ when compared with control pigs and pigs fed Typhimurium. Pigs re-
\end{abstract}

ceiving Choleraesuis had a substantially decreased feed intake on $\mathrm{d} 2,3,4,7,8,9$, and $10(P<0.01)$, with a trend for a reduction on d $5(P=0.08)$, and they experienced an approximately $25 \%$ reduction in BW compared with control pigs and pigs given Typhimurium by the conclusion of the study. Pigs given Choleraesuis also experienced marked reductions in circulating IGFI on $\mathrm{d} 7(P<0.01$ vs. control and Typhimurium), with reductions of lesser magnitude on d 14 ( $P=0.07$ vs. control and $P<0.05$ vs. Typhimurium). Inoculation tended to affect liver IGFBP-3 mRNA $(P=0.08)$, for which expression tended to be elevated in pigs given Typhimurium and Choleraesuis. In contrast, IGFBP-3 mRNA relative abundance was increased $(P<0.03)$ in pigs given Typhimurium compared with control pigs. Muscle IGF-I mRNA was reduced in pigs given Choleraesuis compared with control pigs and pigs given Typhimurium $(P<0.05)$. Treatment tended to affect muscle IGFBP-3 mRNA $(P=0.10)$. Oral inoculation of growing pigs with Choleraesuis disrupted feed intake and BW gain, and this was accompanied by decreases in circulating IGF-I and reduced muscle expression of mRNA for IGF-I and IGFBP-3.

Key words: insulin-like growth factor-I, insulin-like growth factor binding protein-3, insulin-like growth factor binding protein-5, Salmonella, swine

(C)2010 American Society of Animal Science. All rights reserved.

J. Anim. Sci. 2010. 88:1642-1648 doi:10.2527/jas.2009-2259

\section{INTRODUCTION}

Enteric disease and immune challenge are processes that are generally associated with decreased growth in domestic livestock. In swine, oral infection by Salmonella enterica serovar Typhimurium (hereafter referred to as Typhimurium) results in growth suppression and an array of associated physiological effects (Schwartz,

\footnotetext{
${ }^{1}$ Contribution No. 09-387-J from the Kansas Agricultural Experiment Station (Manhattan). The authors thank C. M. Hill (Kansas State University, Manhattan) for technical assistance in the laboratory. The authors gratefully acknowledge partial support from USDA under section 1433 of Public Law 95-113.

${ }^{2}$ Present address: 206f Animal Sciences, University of Nebraska, PO Box 830908, Lincoln 68583-0908.
} 
1999; Balaji et al., 2000; Jenkins et al., 2004). Infection by Salmonella enterica serovar Choleraesuis (hereafter referred to as Choleraesuis), another important swine pathogen, is more likely to cause septicemia in growing pigs (Schwartz, 1999), but little has been reported comparing these 2 serovars in terms of their effects on key regulatory elements of the endocrine growth axis. We have previously shown that infection by Typhimurium results in unmistakable effects on systemic markers of the somatotropic growth axis, namely, serum IGF-I (Balaji et al., 2000; Burkey et al., 2004) and IGFBP-3, in pigs (Jenkins et al., 2004). In the current study, our objective was to directly compare the effects of oral inoculation with Typhimurium and Choleraesuis on weaned pigs because each serovar produces differing effects on swine, with Typhimurium producing mainly self-limiting enteritis and Choleraesuis, a so-called swine host-adapted pathogen, being more likely to result in a more serious and occasionally fatal septicemia (Schwartz, 1999). Therefore, we hypothesized that the effects of these 2 serovars in pigs on known promoters of growth in pigs would differ as well.

\section{MATERIALS AND METHODS}

The experimental protocol used in this study was approved by the Kansas State University Institutional Animal Care and Use Committee.

\section{Experimental Design}

The current study reports data from additional tissue collections and measurements made from a previously published study (Fraser et al., 2007). Essential details of that study and others specific to the current report are included here for clarity. Forty-eight weaned pigs were blocked by sex and BW and then randomly assigned to 1 of 3 treatments in a 14-d study. Each treatment had 8 replicates (pens) containing 1 barrow and 1 gilt in each pen. In total, 16 pigs served as negative controls, 16 pigs were repeatedly fed $10^{8} \mathrm{cfu}$ of Typhimurium, and 16 pigs were repeatedly fed $10^{8} \mathrm{cfu}$ of Choleraesuis. All pigs received treatments in the form of hand-fed dough balls. On d 0, pigs were fed $10^{8} \mathrm{cfu}$ of Choleraesuis or Typhimurium in dough balls, with control pigs receiving dough balls without bacteria. Dough balls were then refed on d 3, 7, and 10, resulting in animals receiving treatment twice weekly through the course of the 14-d study. Details of bacterial culture were described previously (Fraser et al., 2007). All pigs were confirmed to be negative for salmonella organisms by fecal culture before inclusion in the study.

Pig BW were recorded on d 0, 7, and 14, and feeders were weighed daily to estimate ADFI. Rectal temperatures were obtained daily from $1 \mathrm{pig} / \mathrm{pen}$ (same animal each day) from $\mathrm{d} 0$ of the study until $7 \mathrm{~d}$ postchallenge. Serum samples were also taken from $1 \mathrm{pig} / \mathrm{pen}$ (same animal as for rectal temperature) on d 0,7 , and 14 to assay for circulating IGF-I. All pigs were killed at the conclusion of the study, and tissue samples of semitendinosus muscle and liver were taken for analysis of IGF-I, IGFBP-3, and IGFBP-5 mRNA expression. All tissue samples were rapidly frozen in liquid nitrogen after collection.

\section{Serum Analysis}

Serum was collected from a single pig/pen for analysis of circulating IGF-I on d 0, 7, and 14. Serum was subsequently analyzed for circulating IGF-I concentrations via an immunoradiometric assay described previously for use in swine (Balaji et al., 2000).

\section{RNA Extraction and Reverse Transcription}

Samples of muscle and liver tissue were subjected to total RNA extraction using TRI-Reagent (Sigma Corporation, St. Louis, MO) according to the protocol of the manufacturer. After RNA isolation, removal of contaminating genomic DNA was performed with a DNA-free kit (Ambion Inc., Austin TX). Further quantification of isolated total RNA was done by spectrophotometry, using an optical density of $260 \mathrm{~nm}$. Quality of total RNA was assessed by visualization of the $28 \mathrm{~S}$ and $18 \mathrm{~S}$ rRNA after electrophoresis of samples at $100 \mathrm{~V}$ for $1 \mathrm{~h}$ through 1\% agarose-formaldehyde gels with ethidium bromide staining. Reverse transcription was performed using Taqman reverse transcription reagents (Applied Biosystems, Foster City, CA) and was conducted in a $50-\mu \mathrm{L}$ final volume consisting of $25 \mathrm{~m} M$ magnesium chloride, $500 \mu M$ deoxynucleotide 5 '-triphosphate, 2.5 $\mu M$ random hexamers, $0.4 \mathrm{U} / \mu \mathrm{L}$ of ribonuclease inhibitor, and $50 \mathrm{U} / \mu \mathrm{L}$ of MultiScribe reverse transcriptase and Taqman reverse transcription buffer. The reverse transcription mixture was then incubated at $25^{\circ} \mathrm{C}$ for $10 \mathrm{~min}$, heated to $37^{\circ} \mathrm{C}$ for $60 \mathrm{~min}$, and inactivated at $95^{\circ} \mathrm{C}$ for $5 \mathrm{~min}$. The resultant $\mathrm{cDNA}$ was then stored at $-80^{\circ} \mathrm{C}$ until later use.

\section{Real-Time PCR Analysis for Gene Expression}

Real-time quantitative PCR was used to measure the relative abundance of mRNA for IGF-I, IGFBP-3, IGFBP-5, and 18S rRNA in skeletal muscle and hepatic tissues. The PCR reactions were carried out in 96-well plates using $900 \mathrm{n} M$ of the appropriate forward and reverse primers along with $200 \mathrm{n} M$ of the appropriate Taqman detection probe, PCR Mastermix (Applied Biosystems), and $3.5 \mu \mathrm{L}$ of the cDNA sample. The porcine specific primers and detection probes were synthesized from published GenBank sequences using Primer Express software (Applied Biosystems) and were identical to those published previously (Brown et al., 2007).

\section{Statistical Analyses}

Data were analyzed using the MIXED procedure (SAS Inst. Inc., Cary, NC). Data for rectal tempera- 

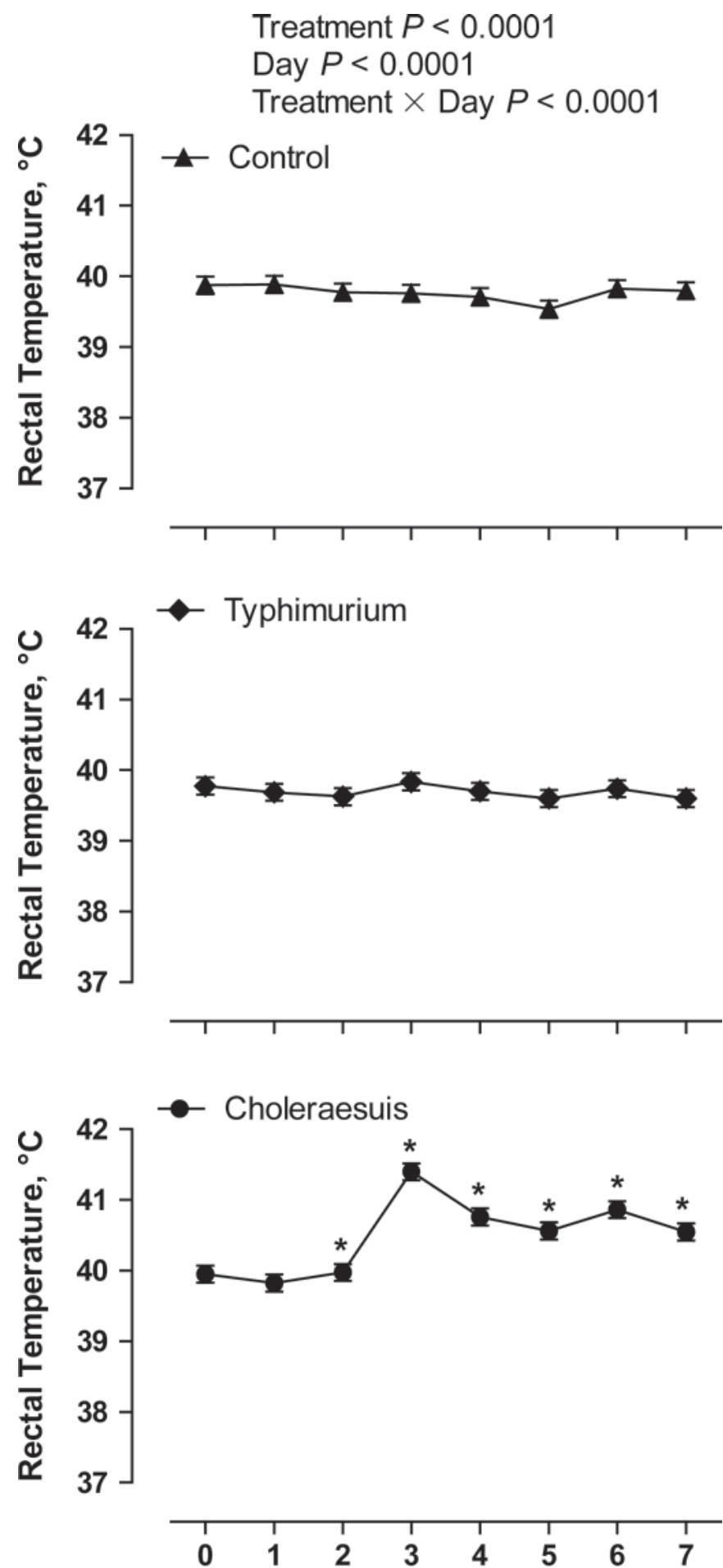

Time After First Salmonella Treatment, d

Figure 1. Rectal temperatures of pigs orally administered $10^{8} \mathrm{cfu}$ of Salmonella enterica serovar Typhimurium or Choleraesuis from d 0 through 7 after challenge. Bacteria were fed on d 0, 3, 7, and 10. Control pigs received dough balls without bacteria. Asterisks indicate days when rectal temperatures in pigs given Choleraesuis were increased relative to control pigs and pigs given Typhimurium $(P<0.05)$. Bars associated with symbols represent the SEM.

ture, ADFI, BW, and serum IGF-I concentrations were analyzed as a randomized block design with repeated measures over time for each experimental unit (pens). Terms for the fixed effects of disease challenge, time, and their interactions were included, with block and pen being considered random effects. Relative abundance of mRNA for genes of interest was calculated relative to $18 \mathrm{~S}$ rRNA. Muscle and liver mRNA data were also analyzed via the MIXED procedure, but without terms for repeated measures and without time statements included in the model. Pen was also considered the experimental unit for all mRNA data. All means expressed are least squares means.

\section{RESULTS}

Rectal temperatures were monitored daily from $\mathrm{d} 0$ through 7 after the first bacterial feeding. There were no differences in rectal temperatures between control and Typhimurium-fed pigs in the first $7 \mathrm{~d}$ after challenge (Figure 1). In contrast, pigs given Choleraesuis experienced increased rectal temperatures beginning on d 2 and continuing through the end of the monitoring period at $\mathrm{d} 7$ when compared with both control and Typhimurium-fed pigs $(P<0.05)$.

Average daily feed intake was measured by weighing feeders for each pen of pigs within each treatment daily (Figure 2), and was monitored from d 0 through the completion of the study on d 14. In general, ADFI between control pigs and pigs given Typhimurium did not differ $(P>0.10)$, with the exception that ADFI tended to be less in Typhimurium on $\mathrm{d} 14(P=0.08)$. Conversely, Choleraesuis-challenged pigs had reduced ADFI on $\mathrm{d} 2,3,4,7,8,9$, and $10(P<0.01)$ and a tendency for reduced ADFI on d $5(P=0.08)$.

Body weights were obtained by weighing pigs on $\mathrm{d} 0$, 7, and 14 (Figure 3). Pigs were initially blocked by BW so, as expected, there were no differences in BW across treatments at d 0. However, pigs fed Choleraesuis had reduced BW on d 7 and 14 compared with control pigs and pigs given Typhimurium $(P<0.01)$.

Circulating IGF-I concentrations (Figure 4) were not different on d 0 between the control, Typhimurium, and Choleraesuis treatments. Moreover, serum IGFI in control pigs and pigs receiving the Typhimurium treatment remained similar through d 14. In contrast, pigs challenged with Choleraesuis had less circulating IGF-I on d 7 when compared with both control and Typhimurium-fed pigs $(P<0.01)$. In addition, Choleraesuis-fed pigs had reductions in serum IGF-I on d 14 when compared with control pigs $(P<0.07)$ and pigs given Typhimurium $(P<0.05)$.

Relative abundance of mRNA for IGF-I, IGFBP-3, and IGFBP-5 (Figure 5) in liver tissue of pigs across all treatments was variable. Only 1 treatment difference was observed for hepatic tissue, with Typhimurium-fed pigs having a greater relative abundance of IGFBP-3 mRNA compared with control pigs $(P<0.03)$. However, in the statistical model for hepatic IGFBP-3, it should be noted that the main effect of treatment only approached significance, at $P=0.08$.

For muscle tissue (Figure 6), pigs challenged with Choleraesuis had reductions in IGF-I mRNA expression 
when compared with control $(P<0.04)$ and Typhimurium-fed pigs $(P<0.002)$. In addition, Choleraesuis-fed pigs had reductions in IGFBP-3 mRNA expression in skeletal muscle when compared with control pigs $(P<$ $0.03)$, although the overall treatment effect in the statistical model only tended to be significant $(P=0.10)$.

\section{DISCUSSION}

Our laboratory has published findings from weaned pigs challenged with the same isolate of Typhimurium as used in the current study and we have noted its effects on several variables in pigs, including known systemic mediators of growth and development (Balaji et al., 2000; Turner et al., 2002a,b; Jenkins et al., 2004). However, the single oral dosages used for bacterial challenge were greater in the previous experiments, ranging from $10^{9}$ to $10^{10} \mathrm{cfu}$. In the current experiment, we modified the approach to include an isolate of Choleraesuis to compare with Typhimurium and we used a smaller dose of bacteria $\left(10^{8} \mathrm{cfu}\right)$ but administered it repeatedly. This was done to model more closely the fecal-oral transmission of salmonella organisms often found in intense swine management and production conditions. We reasoned that, given the institutional animal compliance requirement to wash pens daily, a bacterial load comparable with production conditions might not accumulate unless pigs were purposefully given repeated small-dose exposure. In addition, we included repeated exposure to Typhimurium and Choleraesuis in an effort to create a model of disease-associated growth suppression.

In the current study, we tracked rectal temperature, ADFI, and BW as ancillary measures to document the course of treatment-induced enteric disease. Growth performance data for this experiment were reported previously (Fraser et al., 2007). Clearly, all these measures were affected adversely by repeated oral exposure of pigs to Choleraesuis. In contrast, none of these measures was affected by repeated exposure of pigs to Typhimurium (current report; Fraser et al., 2007). Although we expected Typhimurium to disrupt ADFI, and thereby potentially reduce $\mathrm{BW}$, the oral dose of Typhimurium used in the study was small relative to oral doses reported to provoke enteric disease (Schwartz, 1999) and relative to those we have used previously (Balaji et al., 2000; Turner et al., 2002a,b). Moreover, although we did not formally track fecal shedding of Typhimurium, we are certain live Typhimurium organisms were being consumed and shed in the feces because organisms for refeeding were successfully cultured from fecal collections pooled from pens of pigs inoculated orally with Typhimurium.

We evaluated circulating IGF-I because it is widely accepted that IGF-I can be evaluated as a marker of performance and growth (Florini et al., 1996; Oksbjerg et al., 2004; Sheffield-Moore and Urban, 2004). Furthermore, it is established that bacterial infection (Balaji et al., 2000) and other noninfectious models of sepsis
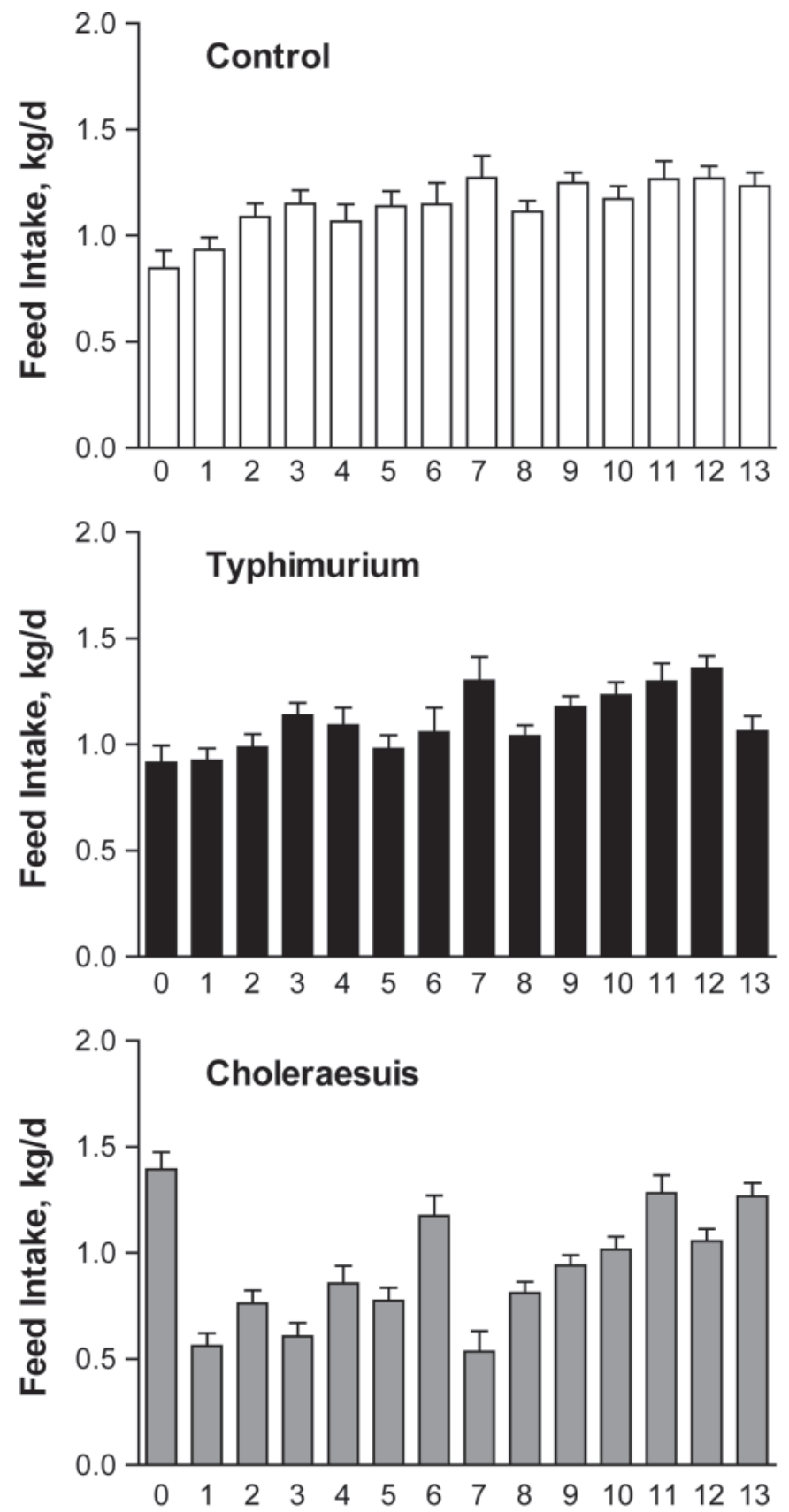

Time After First Salmonella Treatment, $d$

Treatment $P<0.0001$

Day $P<0.0001$

Trt $\times$ Day $\quad P<0.0001$

Figure 2. Average daily feed intake of control pigs and pigs orally administered $10^{8}$ cfu of Salmonella enterica serovar Typhimurium or Choleraesuis. Bacteria were fed on d 0,3, 7, and 10. Control pigs received dough balls without bacteria. Pigs fed Choleraesuis experienced reductions in intake on $\mathrm{d} 2,3,4,7,8,9$, and $10(P<0.01)$, with a trend for a reduction on d $5(P=0.08)$ when compared with control pigs. Trt $=$ treatment. Error bars represent the SEM.

(Orellana et al., 2002; Thissen et al., 2005) can lead to decreases in IGF-I in circulation, with these decreases often paralleling reductions in feed intake. In the current study, pigs challenged with Typhimurium consistently had circulating IGF-I concentrations very similar to those of control pigs. Although this contrasts with 

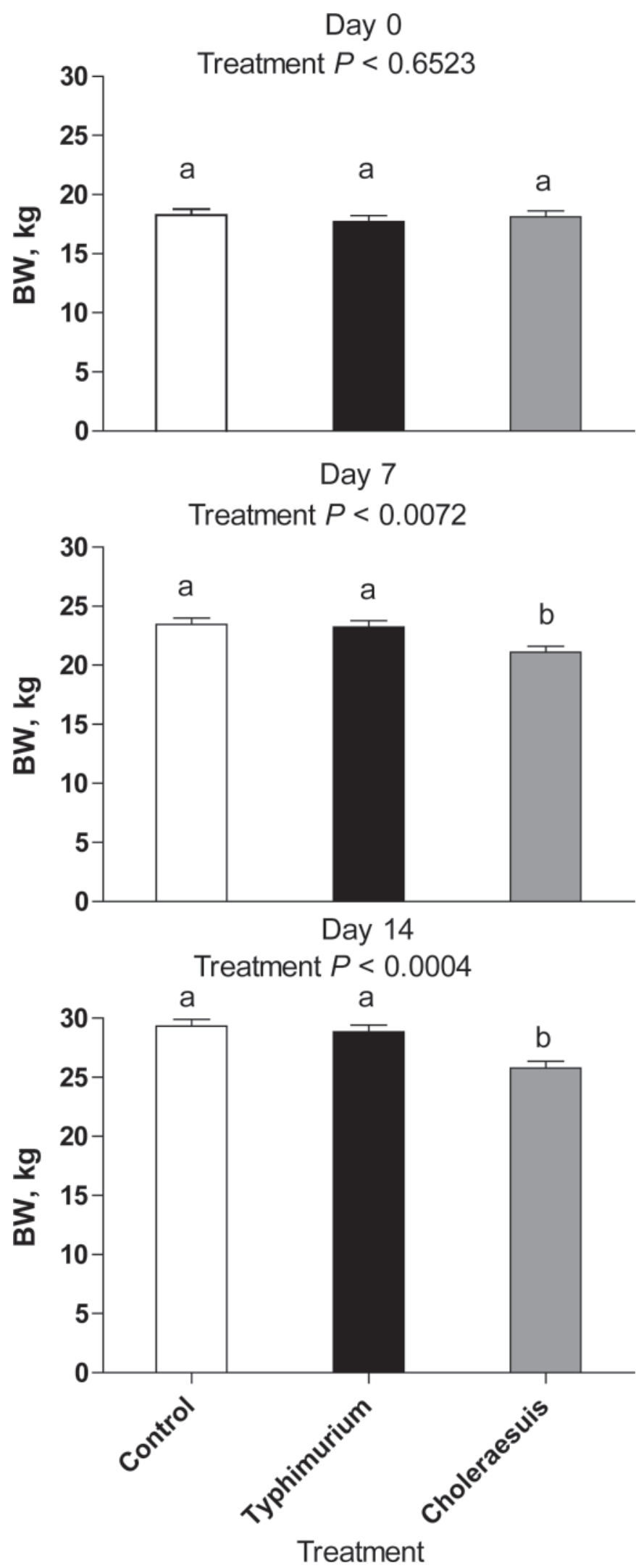

Figure 3. Body weights of control pigs and pigs orally administered $10^{8}$ cfu of Salmonella enterica serovar Typhimurium or Choleraesuis. Bacteria were fed on d 0, 3, 7, and 10. Control pigs received dough balls without bacteria. Pigs receiving Choleraesuis weighed less on $\mathrm{d} 7$ and 14 compared with control pigs and pigs fed Typhimurium (a vs. b, $P<0.01$ ). Error bars represent the SEM.

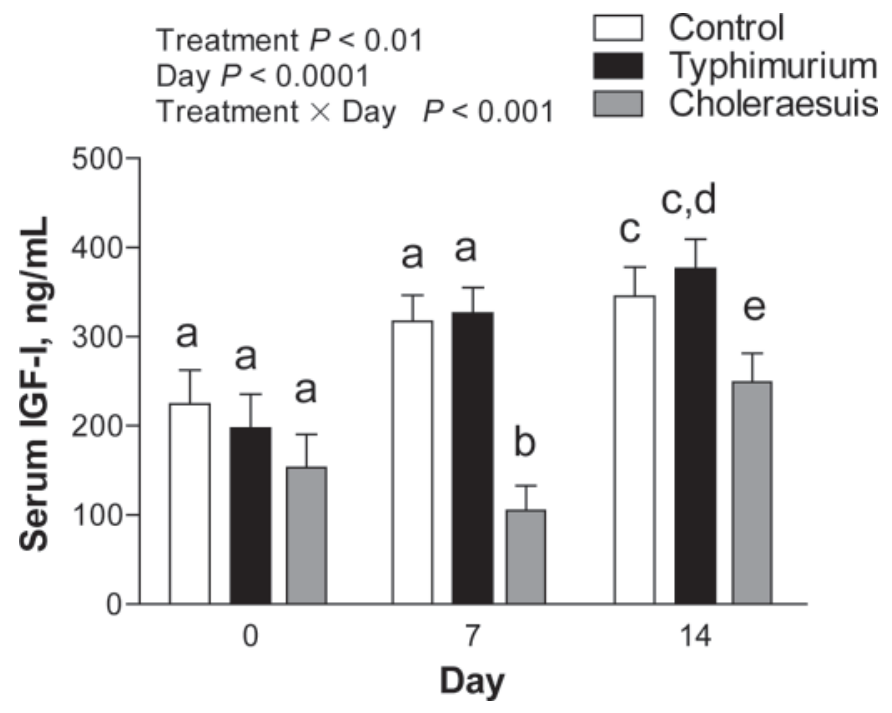

Figure 4. Serum IGF-I concentrations in control pigs and pigs orally administered $10^{8} \mathrm{cfu}$ of Salmonella enterica serovar Typhimurium or Choleraesuis. Bacteria were fed on d 0, 3, 7, and 10. Control pigs received dough balls without bacteria. Bars without common letters within a day differ (a vs. b, $P<0.01$; c vs. e, $P=0.07$; d vs. e, $P$ $<0.05)$. Error bars represent the SEM.

previous findings from our group for pigs challenged with Typhimurium (Balaji et al., 2000; Turner et al., 2002a,b; Jenkins et al., 2004), the finding is consistent with the lack of effect of Typhimurium on ADFI in the current study, which we think is likely a consequence of the smaller dose of Typhimurium used here.

In contrast to pigs receiving Typhimurium, pigs receiving Choleraesuis at this same dosage experienced marked reductions in serum IGF-I. This observation is consistent with other pathophysiological effects of Choleraesuis observed in the current study, most notably treatment-induced reductions in ADFI. However, of potentially greater significance is our finding that, in addition to circulating IGF-I, pigs challenged with Choleraesuis experienced reduced steady-state abundance of muscle mRNA for both IGF-I and IGFBP-3. Although decreases in IGF-I mRNA in skeletal muscle have been documented after administration of lipopolysaccharide (Fan et al., 1994; Fernández-Celemín et al., 2002), our findings in the current study indicate what we believe to be the first chronic disease model that has been documented to disrupt IGF-I and IGFBP-3 locally in skeletal muscle. Our working hypothesis is that these effects are most probably related to the decreased feed intakes of pigs challenged with Choleraesuis because there is a strong body of evidence that nutrient intake plays a major role in the regulation and expression of critical mediators of growth (Breier, 1999; Ling and Bistrian, 2005; Thissen et al., 2005). Although the effect of Choleraesuis in reducing skeletal muscle mRNA for IGFBP-3 is consistent with reduced muscle IGF-I mRNA, we caution that the overall treatment effect for IGFBP-3 mRNA only approached significance.

Emerging dogma linking disease to mechanisms of reduced growth potential suggests that changes in feed intake, often found with animals experiencing a dis- 
Treatment $P=0.48$

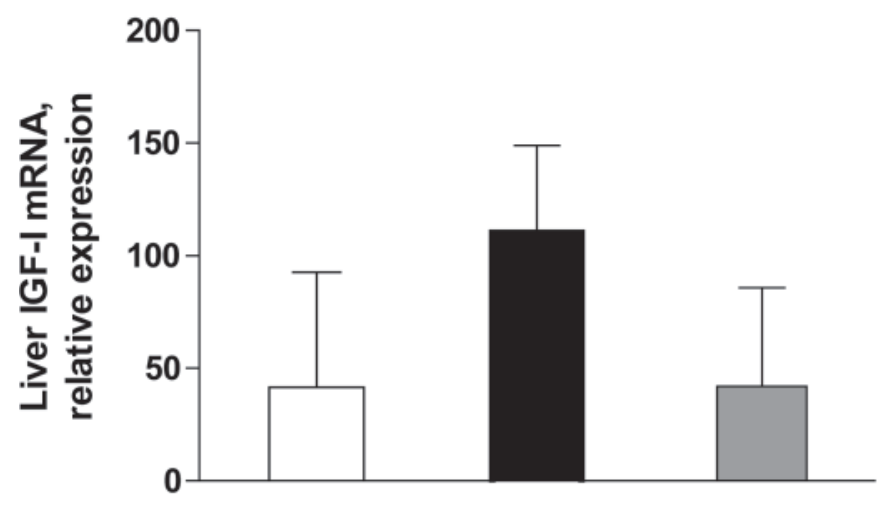

Treatment $P=0.08$

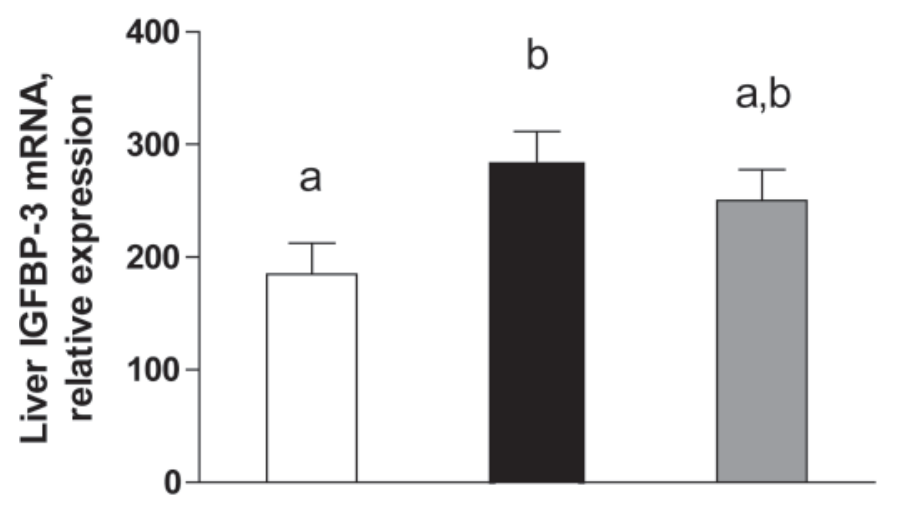

Treatment $P=0.13$

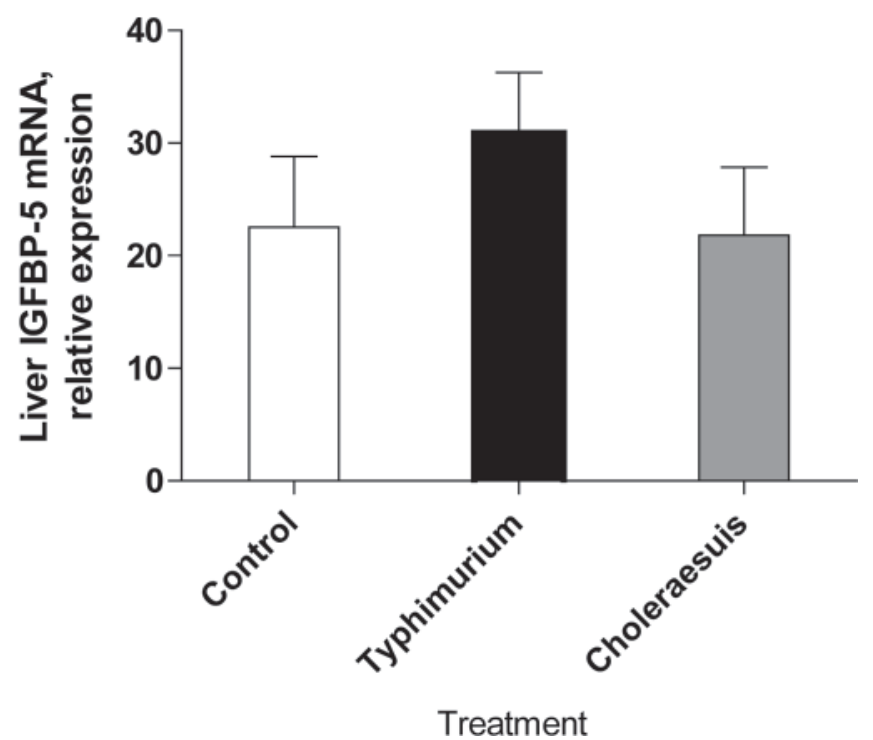

Figure 5. Expression of IGF-I, IGFBP-3, and IGFBP-5 mRNA in liver tissue of control pigs and pigs orally administered $10^{8} \mathrm{cfu}$ of Salmonella enterica serovar Typhimurium or Choleraesuis. Bacteria were fed on d $0,3,7$, and 10 . Control pigs received dough balls without bacteria. Pigs were killed on d 14. For liver IGFBP-3 mRNA, bars without common letters differ (a vs. b, $P<0.03$ ). Error bars represent the SEM.
Treatment $P<0.01$

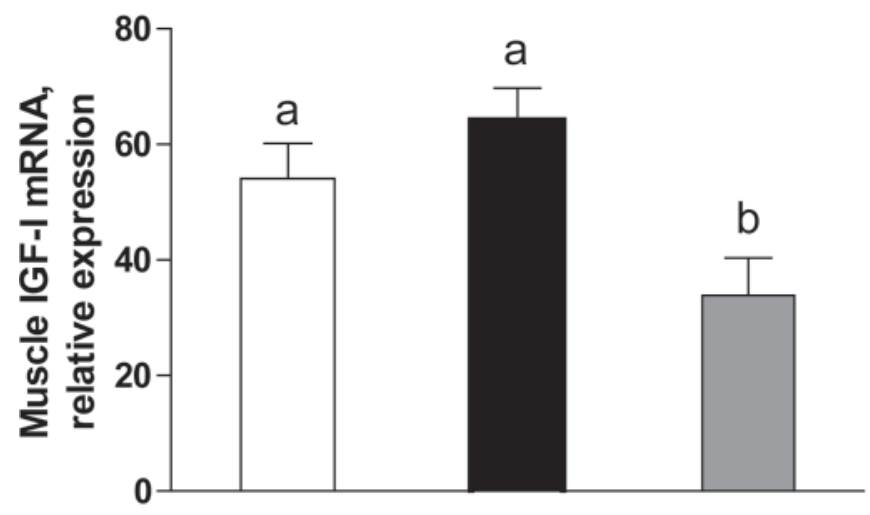

Treatment $P=0.10$

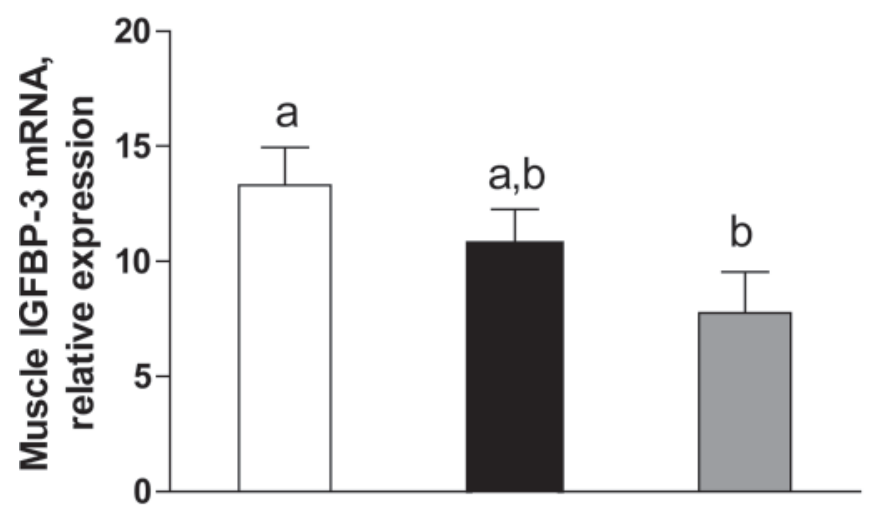

Treatment $P=0.53$

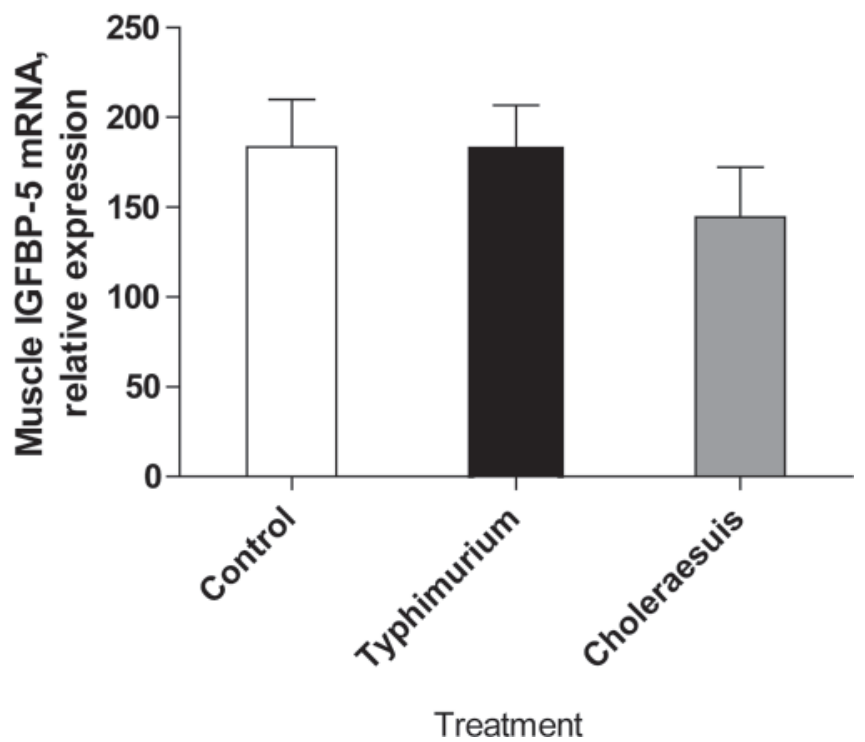

Figure 6. Expression of IGF-I, IGFBP-3, and IGFBP-5 in semitendinosus muscle tissue of control pigs and pigs orally administered $10^{8}$ cfu of Salmonella enterica serovar Typhimurium or Choleraesuis. Bacteria were fed on d $0,3,7$, and 10 . Control pigs received dough balls without bacteria. Pigs were killed on d 14. For muscle IGF-I mRNA and IGFBP-3 mRNA, bars without common letters differ (a vs. b, $P$ $<0.05)$. Error bars represent the SEM. 
ease challenge, are manifested by elevated peripheral proinflammatory cytokines (Kelley et al., 1993; Johnson, 1997), with tumor necrosis factor- $\alpha$, IL-1, and IL-6 being predominantly implicated in altering metabolism and growth (Spurlock, 1997). It is of interest to note that in the companion study conducted with pen mates of pigs from the current study, Choleraesuis challenge was not associated with increased circulating tumor necrosis factor- $\alpha$ or IL-1 $\beta$ (Fraser et al., 2007). However, it is important to note that local production of inflammatory cytokines not measured in the current study may be of greater importance and more reflective of local regulation of skeletal muscle growth than systemic cytokines (reviewed in Gabler and Spurlock, 2008).

Although pigs challenged with repeated oral doses of Choleraesuis experienced reductions in IGF-I and IGFBP-3 mRNA in skeletal muscle, these treatment effects were not found in hepatic tissue. In fact, the only effect in hepatic tissues was an elevation in IGFBP-3 mRNA in pigs fed Typhimurium compared with control pigs, with pigs fed Choleraesuis being intermediate between the other treatments. The physiological significance of this isolated effect is not readily apparent, especially in the context of no other treatment effects of repeated Typhimurium feeding at the dose used in the current study. Moreover, the overall treatment effect in the statistical model, like that of muscle IGFBP-3 mRNA, only approached significance. Hence, this trend should be considered with caution.

In conclusion, data from the current study document, for the first time in pigs, both systemic and local perturbation of the IGF system in skeletal muscle associated with Choleraesuis-induced disease. Although we expected a priori effects of Typhimurium, at least on systemic IGF-I, the lack of effect of Typhimurium at the dose used in the current study supports our hypothesis of serovar-specific effects on growth in pigs. Perhaps these effects reflect the more systemic nature of Choleraesuis in contrast to the more enteric nature of Typhimurium. Whether local effects on regulation of the muscle IGF system are common to other enteric diseases of swine and whether greater doses of Typhimurium would result in similar kinds of changes are intriguing questions for future research.

\section{LITERATURE CITED}

Balaji, R., K. J. Wright, C. M. Hill, S. S. Dritz, E. L. Knoppel, and J. E. Minton. 2000. Acute phase responses of pigs challenged orally with Salmonella typhimurium. J. Anim. Sci. 78:18851891.

Breier, B. H. 1999. Regulation of protein and energy metabolism by the somatotropic axis. Domest. Anim. Endocrinol. 17:209218.

Brown, K. R., R. D. Goodband, M. D. Tokach, S. S. Dritz, J. L. Nelssen, J. E. Minton, J. J. Higgins, J. C. Woodworth, and B. J. Johnson. 2007. Growth characteristics, blood metabolites, and insulin-like growth factor system components in maternal tissues of gilts fed L-carnitine through day seventy of gestation. J. Anim. Sci. 85:1687-1694.

Burkey, T. E., S. S. Dritz, J. C. Nietfeld, B. J. Johnson, and J. E. Minton. 2004. Effect of dietary mannanoligosaccharide and sodium chlorate on the growth performance, acute-phase response, and bacterial shedding of weaned pigs challenged with Salmonella enterica serotype Typhimurium. J. Anim. Sci. 82:397-404.

Fan, J., P. E. Molina, M. C. Gelato, and C. H. Lang. 1994. Differential tissue regulation of insulin-like growth factor-I content and binding proteins after endotoxin. Endocrinology 134:16851692.

Fernández-Celemín, L., N. Pasko, V. Blomart, and J. P. Thissen. 2002. Inhibition of muscle insulin-like growth factor I expression by tumor necrosis factor- $\alpha$. Am. J. Physiol. Endocrinol. Metab. 283:E1279-E1290.

Florini, J. R., D. Z. Ewton, and S. A. Coolican. 1996. Growth hormone and the insulin-like growth factor system in myogenesis. Endocr. Rev. 17:481-517.

Fraser, J. N., B. L. Davis, K. A. Skjolaas, T. E. Burkey, S. S. Dritz, B. J. Johnson, and J. E. Minton. 2007. Effects of feeding Salmonella enterica serovar Typhimurium or serovar Choleraesuis to weaned pigs on growth performance and circulating insulin-like growth factor-I, tumor necrosis factor $\alpha$, and interleukin-1 $\beta$. J. Anim. Sci. 85:1161-1167.

Gabler, N. K., and M. E. Spurlock. 2008. Integrating the immune system with the regulation of growth and efficiency. J. Anim. Sci. 86(E-Suppl.):E64-E74.

Jenkins, N. L., J. L. Turner, S. S. Dritz, S. K. Durham, and J. E. Minton. 2004. Changes in circulating insulin-like growth factor-I, insulin-like growth factor binding proteins, and leptin in weaned pigs infected with Salmonella enterica serovar Typhimurium. Domest. Anim. Endocrinol. 26:49-60.

Johnson, R. W. 1997. Inhibition of growth by pro-inflammatory cytokines: An integrated view. J. Anim. Sci. 75:1244-1255.

Kelley, K. W., S. Kent, and R. Dantzer. 1993. Why sick animals don't grow: An immunological explanation. Pages 119-132 in Growth of the Pig. G. R. Hollis, ed. CAB Int., Wallingford, UK.

Ling, P., and B. R. Bistrian. 2005. Nutrition and IGF proteins in chronic malnutrition and critical illness. Pages 53-74 in IGF and Nutrition in Health and Disease. M. S. Houston, J. M. P. Holly, and E. L. Feldman, ed. Humana Press, Totowa, NJ.

Oksbjerg, N., F. Gondret, and M. Vestergaard. 2004. Basic principles of muscle development and growth in meat-producing mammals as affected by the insulin-like growth factor (IGF) system. Domest. Anim. Endocrinol. 27:219-240.

Orellana, R. A., P. M. J. O'Connor, H. V. Nguyen, J. A. Bush, A. Suryawan, M. C. Thivierge, M. L. Fiorotto, and T. A. Davis. 2002. Endotoxemia reduces skeletal muscle protein synthesis in neonates. Am. J. Physiol. Endocrinol. Metab. 283:E909E916.

Schwartz, K. J. 1999. Salmonellosis. Pages 535-552 in Diseases of Swine. B. E. Straw, S. D'Allaire, W. L. Mengeling, and D. J. Taylor, ed. Iowa State Univ. Press, Ames.

Sheffield-Moore, M., and R. J. Urban. 2004. An overview of the endocrinology of skeletal muscle. Trends Endocrinol. Metab. $15: 110-115$

Spurlock, M. E. 1997. Regulation of metabolism and growth during immune challenge: An overview of cytokine function. J. Anim. Sci. 75:1773-1783.

Thissen, J. P., V. Beauloye, J. M. Ketelslegers, and L. E. Underwood. 2005. Regulation of insulin-like growth factor-I by nutrition. Pages 25-52 in IGF and Nutrition in Health and Disease. M. S. Houston, J. M. P. Holly, and E. L. Feldman, ed. Humana Press, Totowa, NJ.

Turner, J. L., S. S. Dritz, J. J. Higgins, K. L. Herkelman, and J. E. Minton. 2002a. Effects of a Quillaja saponaria extract on growth performance and immune function of weanling pigs challenged with Salmonella typhimurium. J. Anim. Sci. 80:1939-1946.

Turner, J. L., S. S. Dritz, J. J. Higgins, and J. E. Minton. 2002b. Effects of Ascophyllum nodosum extract on growth performance and immune function of young pigs challenged with Salmonella typhimurium. J. Anim. Sci. 80:1947-1953. 